OPEN ACCESS

Edited by:

Cesar Moran,

University of Texas MD Anderson

Cancer Center, United States

Reviewed by:

Paul Emile Van Schil,

Antwerp University Hospital, Belgium Jelena Stojsic

University of Belgrade, Serbia

${ }^{*}$ Correspondence: Anja C. Roden

roden.anja@mayo.edu

Specialty section:

This article was submitted to

Thoracic Oncology,

a section of the journal

Frontiers in Oncology

Received: 27 November 2021

Accepted: 10 January 2022

Published: 07 February 2022

Citation:

Roden AC, Rakshit S, Johnson GB, Jenkins SM and Mansfield AS (2022) Correlation of Somatostatin Receptor 2 Expression, 68Ga-DOTATATE PET

Scan and Octreotide Treatment

in Thymic Epithelial Tumors.

Front. Oncol. 12:823667.

doi: 10.3389/fonc.2022.823667

\section{Correlation of Somatostatin Receptor 2 Expression, 68Ga-DOTATATE PET Scan and Octreotide Treatment in Thymic Epithelial Tumors}

\author{
Anja C. Roden ${ }^{1 *}$, Sagar Rakshit ${ }^{2}$, Geoffrey B. Johnson ${ }^{3,4}$, Sarah M. Jenkins ${ }^{5}$ \\ and Aaron S. Mansfield ${ }^{2}$ \\ ${ }^{1}$ Department of Laboratory Medicine and Pathology, Mayo Clinic, Rochester, MN, United States, ${ }^{2}$ Division of Medical \\ Oncology, Mayo Clinic, Rochester, MN, United States, ${ }^{3}$ Department of Radiology, Mayo Clinic, Rochester, MN, \\ United States, ${ }^{4}$ Department of Immunology, Mayo Clinic, Rochester, MN, United States, ${ }^{5}$ Division of Clinical Trials \\ and Biostatistics, Mayo Clinic, Rochester, MN, United States
}

Somatostatin receptor 2 (SSTR2) has been shown to be expressed in a subset of neuroendocrine tumors and carcinomas and plays a role in imaging studies and guiding therapy. Patients with tumors expressing SSTR2 may be successfully treated with somatostatin inhibitors or radiolabeled somatostatin analogues. We studied SSTR2 expression in TET and correlated it with 68Ga-DOTATATE PET/CT or 68GaDOTATATE PET/MR results and treatment outcome. An institutional database of TET was searched for thymoma, thymic carcinoma, and thymic neuroendocrine tumor (TNET) with available resection specimens. Cases were subtyped (2021 WHO classification) and staged ( $8^{\text {th }}$ AJCC/UICC staging). A section was stained with anti-SSTR2 antibody (clone UMB1). Percent tumor cells with membranous staining was recorded if present in $\geq 1 \%$ of tumor cells. Medical records were searched for 68Ga-DOTATATE PET scans and treatment. Statistical analysis was performed. Eighty patients (1969-2021) with a median age of 61.3 years (range, 19.1-87.3) (37 males, 46.3\%) had thymic carcinoma $(\mathrm{N}=33)$, TNET ( $\mathrm{N}=7)$, or thymoma ( $\mathrm{N}=40)$. SSTR2 expression was identified in 29 (of 80, $36.3 \%)$ TET including $2 / 2(100 \%)$ small cell carcinomas, $2 / 5$ (40.0\%) atypical carcinoid tumors, 16/23 (69.6\%) squamous cell carcinomas, 2/2 (100\%) lymphoepithelial carcinomas, $1 / 1$ (100\%) adenosquamous carcinoma, and 6/40 (15.0\%) thymomas. SSTR2 expression in $\geq 50 \%$ of tumor cells (vs $1-49 \%$ ) was associated with younger age $(p=0.023)$ and shorter recurrence/metastasis-free survival $(p=0.007)$. 68Ga-DOTATATE PET scans $(\mathrm{N}=9)$ revealed a Krenning score of 3 in patients with atypical carcinoid tumor, small cell carcinoma, and squamous cell carcinoma ( $\mathrm{N}=1$ each) with SSTR2 expression in 95,100 , and $5 \%$ of tumor cells, respectively. Scans with Krenning scores of $\leq 2(N=5)$ were seen in tumors with no SSTR2 expression in $80 \%$ of cases and a single atypical carcinoid tumor with SSTR2 expression in 10\% of tumor cells. One scan resulted as "increased uptake" was in a patient with no SSTR2 expression. In conclusion, 68Ga-DOTATATE PET 
scans correlated with SSTR2 expression in TET in most patients and appeared to be useful to identify patients with TET who may be amenable to treatment with somatostatin analogues. Larger studies including more patients with 68Ga-DOTATATE PET scans are necessary to independently and prospectively validate our findings.

Keywords: somatostatin receptor 2, SSTR2, DOTATATE scan, octreotide treatment, thymoma, thymic carcinoma, atypical carcinoid tumor, thymic neuroendocrine tumor

\section{INTRODUCTION}

Thymic epithelial tumors (TET) including thymomas, thymic carcinomas, and thymic neuroendocrine tumors (TNET) are malignant neoplasms. Although these tumors are rare, they together represent the most common solitary lesions in the prevascular mediastinum (1). Specifically thymic carcinomas and TNETs are often diagnosed at high stage and their large size and infiltration of vital organs commonly prevents complete resection. For instance, 71 to $79 \%$ of patients with thymic carcinoma present at stages III or IV and complete resection is reported in only 46 to $69 \%$ of patients with 5 -year overall survival rates of 52 to $64 \%$ and disease-free survival of $41 \%(2-6)$. In TNET, the outcome depends on the histologic subtype with 5year overall survivals of 50 to $70 \%$ for typical and atypical carcinoid tumors, 30 to $66 \%$ for large cell neuroendocrine carcinomas, and $0 \%$ with a median survival of 13-26 months for small cell carcinomas (7).

Predictive biomarkers are scarce in TET and therefore options for targetable therapy are currently very limited. Thymomas and thymic carcinomas have very low tumor mutational burdens with 0.48 mutations and 1.2 mutations/ $\mathrm{Mb}$, respectively with a rare thymic carcinoma reported to harbor 21.3 mutations/Mb (8-10). GTF2I mutation is the most common molecular alteration in TET, specifically in type A and $\mathrm{AB}$ thymomas where it occurs in 70 to $100 \%$ of cases. In contrast to thymomas, GTF2I mutation is only identified in 0 to $8 \%$ of thymic carcinomas, and has not been described in TNETs $(8,10$, 11). Moreover, no therapies are currently available to target GTF2I. KIT mutations occur in 6 to $20 \%$ of thymic carcinomas although only a few tumors harbor an activating KIT mutation and therefore only some patients may benefit from receptor tyrosine kinase inhibitors (12-14). Other mutations in thymic carcinomas include TP53, CDKN2A, cyclin D1, FGFR3, and ALK among others, some of which may potentially be targetable (8, $12,13,15,16)$. While PD-L1 expression has been identified in 27 to $80 \%$ of thymic carcinomas and 23 to $54 \%$ of thymomas, given the unique immune status of the thymic gland, immune checkpoint inhibitor treatment requires further investigation $(9,17-20)$. Taken together, predictive biomarkers are still strongly sought to predict tumor responsiveness of TET to targeted therapy.

Somatostatin receptor 2 (SSTR2) is a G protein-coupled cell surface receptor in the family of somatostatin receptors that has multiple roles via adenylate cyclase, calcium influx, and has effects on cell cycling angiogenesis, apoptosis, and growth factor signalling $(21,22)$. The activation of the receptor by extracellular ligands has been shown to lead to inhibition of cell proliferation (23). In contrast, in a study of small cell lung carcinomas in which $48 \%$ of tumors expressed SSTR2, high SSTR2 expression (defined in that study as SSTR2 expression in tumor tissue 1+ or greater or immunohistochemical score $\geq 1$ ) was associated with worse 2-year survival when compared to low expression of SSTR2 (21). These results were largely attributed to limited stage disease and not seen in patients with extensive stage disease. The authors concluded that SSTR2 signaling in small cell lung cancer may support tumor growth and maintenance. Indeed, that study further showed that downregulation of SSTR2 leads to increased apoptosis and decreased tumor growth in small cell lung carcinoma (21).

SSTR2 has also been recognized as an imaging and treatment target in various neoplasms including neuroendocrine tumors such as paragangliomas and small cell lung carcinomas, but also other malignancies such as thyroid carcinomas, and EBV-driven and non-EBV-driven nasopharyngeal carcinomas (22, 24-26). There are two primary mechanisms by which treatment may be delivered including 1) SSTR2 analogues that rely on SSTR2 signaling-induced changes and 2) the use of SSTR2 as a targeting molecule to deliver a cytotoxic or radioactive payload in form of an antibody-drug conjugate (22). For instance, DOTATATE and DOTA-Tyr-octreotide (DOTA-TOC) are clinically available somatostatin analogues that bind to SSTR2 (26). Patients with tumors expressing SSTR2 have been shown to be successfully treated with peptide somatostatin inhibitors such as octreotide or DOTATATE (27). These agents can be linked to radionuclides like 68-gallium (68Ga) and 177-lutetium (177Lu) for both imaging and therapeutic applications respectively. For instance, Thakur et al. found that SSTR2 is higher expressed in thyroid carcinomas and medullary carcinomas than in normal thyroid tissue and most patients with metastatic thyroid cancer showed positive 68Ga-DOTATATE uptake indicating that SSTR2 is expressed by these tumors (28). Treatment of mice with 177Lu DOTATATE resulted in tumor growth reduction (28). Furthermore, in a randomized, placebo-controlled study of the somatostatin analogue lanreotide in patients with SSTRpositive (by scintigraphy) grade 1 or 2 neuroendocrine tumors with a Ki-67 proliferative index of $<10 \%$ originating in the pancreas, midgut, or hindgut or of unknown origin lanreotide treatment was associated with significantly prolonged progression-free survival of $65 \%$ at 24 months when compared to $33 \%$ for the placebo group (29).

Although DOTATATE PET scans are part of the clinical workup of some TET, specifically TNETs and octreotide treatment has been used in a subset of TET including 
thymomas, thymic carcinomas, and TNETs, SSTR2 expression has only been studied in small case series or case reports (30-32). Furthermore, the correlation between SSTR2 expression and results of $68 \mathrm{Ga}$-DOTATATE PET scans in TET is largely unknown. Therefore, we studied the expression of SSTR2 in TET and its correlation with results of DOTATATE PET scans and treatment outcome.

\section{METHODS}

\section{Patients}

In this retrospective study, an institutional database of TET (1941-2021) was searched for thymoma, thymic carcinoma, and TNET from patients who underwent surgery. All cases were reviewed by a thoracic pathologist (ACR) to confirm the diagnosis. TETs were subtyped according to the $2021 \mathrm{WHO}$ classification (33) and staged using the $8^{\text {th }}$ AJCC/UICC staging manual (34). To avoid possible misinterpretation of SSTR2expression on tumor cells due to potentially high numbers of SSTR2-expressing thymocytes only type A and B3 thymomas, micronodular thymomas with lymphoid stroma, thymic carcinomas, and TNETs were included in the study. Patient demographics and outcomes were recorded from medical records. Medical records were also searched for $68 \mathrm{Ga}-$ DOTATATE PET scans and treatment. The study was approved by the Mayo Clinic Rochester Institutional Review Board (\#10-003525).

\section{Immunohistochemistry}

Formalin-fixed paraffin-embedded tissue blocks were cut at $4 \mu \mathrm{m}$ and stained with anti-SSTR2 antibody (clone UMB1, Abcam, Boston, MA). Percent tumor cells with membranous staining was recorded if present in $\geq 1 \%$ of tumor cells. The staining evaluation was modified from the evaluation used by Volante et al. (35) Similar to the evaluation system by Volante et al. no expression or focal or diffuse cytoplasmic expression of SSTR2 were regarded as negative. Membranous SSTR2 staining in 1 to $49 \%$ of tumor cells and 50 to $100 \%$ of tumor cells were considered positive. Staining intensity was noted as negative, weak, moderate, or strong.

\section{Ga-DOTATATE PET Scans}

Available 68Ga-DOTATATE PET/CT and PET/MR scans were reviewed by a nuclear medicine physician and radiologist (GBJ) and a Krenning score was applied. Briefly, Krenning score is a qualitative measure of relative uptake of $68 \mathrm{Ga}$-DOTATATE in tumors versus the physiologic uptake in the internal organs of the liver and spleen, with a Krenning score of 1 being negative and tumor activity far below liver activity, a Krenning score of 2 being mildly positive with activity slightly less than liver, a Krenning score of 3 being positive with activity higher than liver, and a Krenning score of 4 being very positive with activity above spleen. Scans were performed on GE Discovery 710, GE Discovery MI and Siemens Vision 600 PET/CT or GE Signa PET/MR scanners. Uptake was 60 minutes plus or minus 5 minutes in all patients, and the injected dose was $5.2 \mathrm{mCi} 68 \mathrm{Ga}-$ DOTATATE IV +/- 10\% IV.

\section{Statistical Analysis}

Continuous and ordinal characteristics were compared between SSTR2 expression groups with Wilcoxon rank-sum tests, and categorical characteristics were compared with Fisher's exact tests. The WHO type was compared using the following compressed categories: thymoma, thymic carcinoma, and thymic neuroendocrine tumors (including small cell carcinomas and atypical carcinoid tumors). Recurrence/ metastasis-free survival (RFS) and overall survival (OS) were compared between groups with likelihood ratio tests from Cox proportional-hazards regression models. Five-year RFS and OS were summarized using the Kaplan-Meier method along with 95\% confidence intervals (CI). P-values less than 0.05 were considered statistically significant. All analyses were performed using SAS version 9.4 (SAS Institute Inc., Cary, NC).

\section{RESULTS}

\section{Patient Characteristics and Tumor Histology}

Eighty patients surgically treated between 1969 and 2021 were included in the study. Demographics of the study population are summarized in Table 1. These 80 patients carried thymomas $(\mathrm{N}=40,50 \%)$, thymic carcinomas $(\mathrm{N}=33,41.3 \%)$, and TNETs $(\mathrm{N}=7,8.8 \%)$. Tumor histology is detailed in Table 2.

The median age of the study population was 61.3 years with a slight female predominance (53.7\%). Patients with thymoma were significantly older at time of surgery than patients with thymic carcinoma (median age [range], 64.6 years [28.1-87.3] vs 52.8 [19.1-79.6], respectively) $(\mathrm{p}=0.02)$ and patients with TNET (median age [range], 64.6 years [28.1-87.3] vs 44.1 [29.7-61.4], respectively) $(\mathrm{p}=0.004)$. There was no difference in age between patients with thymic carcinoma and patients with TNET $(\mathrm{p}=0.11)$. Most patients (85\%) underwent complete resection. The median tumor size of resected tumors was $5.0 \mathrm{~cm}$. Most tumors (52.8\%) were of stage I. Additional neoadjuvant and/or adjuvant therapy was given in $42.9 \%$ of patients; 3 patients also received octreotide.

Follow up was available in 78 patients for a median of 3.1 years (range, 0.1-19.6). The outcome of patients is detailed in Table 1. Twenty-three patients had a metastasis and/or recurrence within 0.2 to 4.5 years after resection of the primary tumor (5-year rate of metastasis/recurrence, $41.3 \%$, 95\% CI: $27.4 \%-55.2 \%$ ). Most patients (43 of 78 ) were alive without disease at the time of last follow-up. Ten (of 78) died due to TET. All patients who died due to disease had either thymic carcinoma or TNET. The 5-year overall survival was 68.1\% (95\% CI: 55.5\%-80.7\%).

\section{SSTR2 Expression of Tumors}

SSTR2 expression (1-100\%) was identified in 29 (of 80, 36.3\%) TET. Results of SSTR2 expression are detailed in Table 2. SSTR2 expression was more common among thymic carcinomas 
TABLE 1 | Demographics, treatment, and outcome of study population.

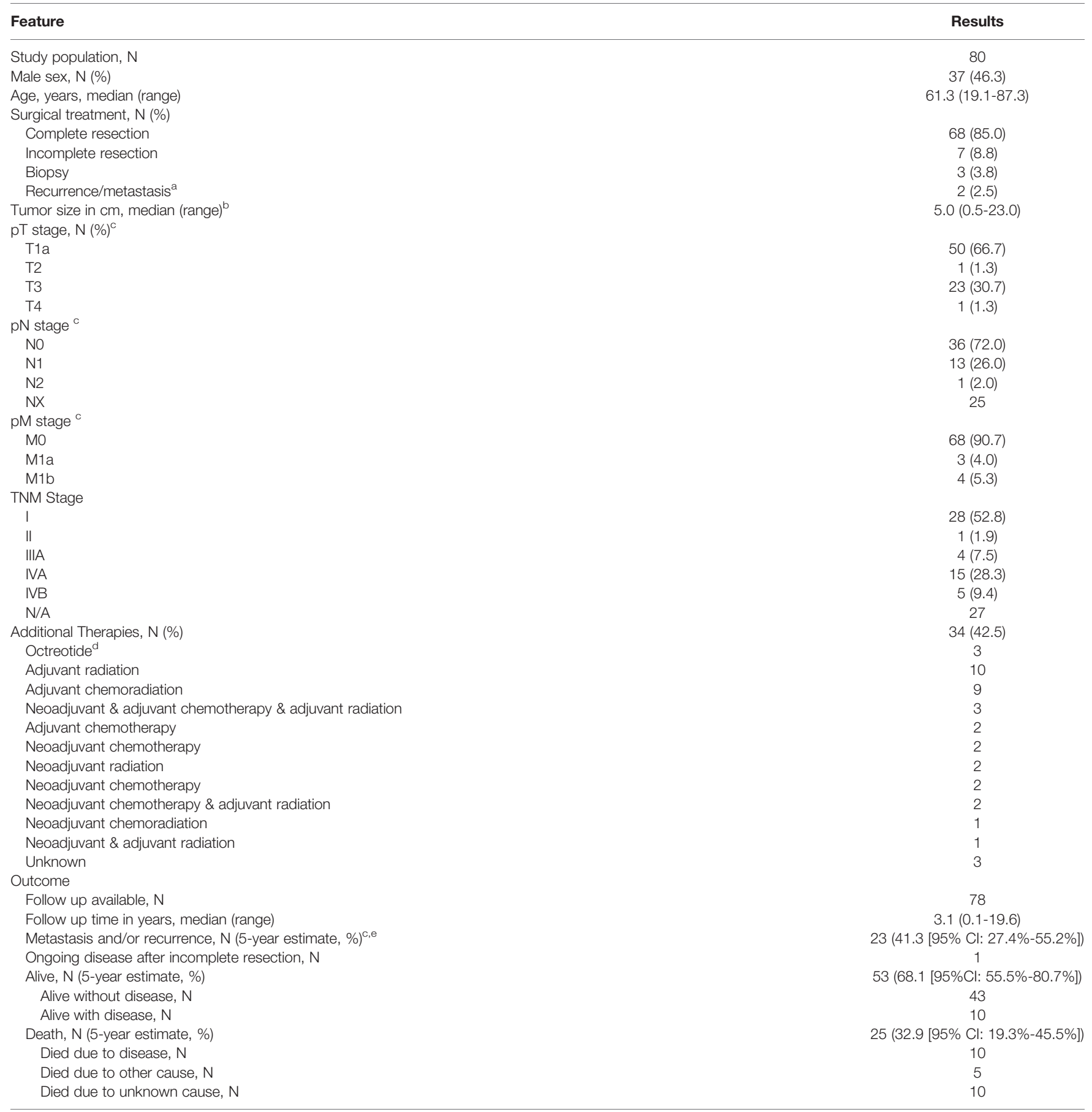

aIn these 2 patients the specimen at time of recurrence/metastasis was tested for SSTR2 expression; date of resection of primary tumor was used for outcome analysis;

${ }^{b}$ Only including completely resected primary tumors;

'Only including resected tumors;

${ }^{d}$ All 3 patients received octreotide in addition to other additional treatment;

${ }^{e}$ Data available in 75 patients; N/A, not available.

(57.6\%) and TNET (57.1\%) as compared to thymomas (15.0\%, $\mathrm{p}<0.001)$ (Table 2). Furthermore, among those expressing SSTR2, there was a trend of higher expression of SSTR2 $(\geq 50 \%)$ in thymic carcinomas (10 of $19,52.6 \%)$ and TNETs $(2$ of $4,50 \%)$ than in thymomas (0 of 6) $(\mathrm{p}=0.07)$ (Table 2).
SSTR2 expression was strong in 19 (of 29, 65.5\%), moderate in 7 (24.1\%), and weak in $3(10.3 \%)$ TET. Weak expression was seen in 2 thymomas with $1 \%$ of tumor cells expressing SSTR2 and in an adenosquamous carcinoma with 5\% of tumor cells expressing SSTR2. 
TABLE 2 | Histopathologic features and expression of SSTR2 in thymic epithelial tumors.

\begin{tabular}{|c|c|c|c|c|c|c|}
\hline Tumor Histology & $\begin{array}{l}\text { Number } \\
\text { of Cases } \\
(\%)\end{array}$ & $\begin{array}{l}\text { Number of } \\
\text { SSTR2- } \\
\text { negative } \\
\text { Cases (\%) }\end{array}$ & $\begin{array}{l}\text { Number of Total Cases } \\
\text { Expressing SSTR2 in } 1-100 \% \text { of } \\
\text { Tumor Cells (\%) (median \% } \\
\text { SSTR-positive tumor cells, } \\
\text { range) }\end{array}$ & $\begin{array}{l}\text { Number of Cases Expressing } \\
\text { SSTR2 in } 1-49 \% \text { of Tumor Cells } \\
\text { (\%) (median \% SSTR-positive } \\
\text { tumor cells, range) }\end{array}$ & $\begin{array}{l}\text { Number of Cases Expressing } \\
\text { SSTR2 in } \geq 50 \% \text { of Tumor Cells } \\
\text { (\%) (median } \% \text { SSTR-positive } \\
\text { tumor cells, range) }\end{array}$ & $\begin{array}{l}\text { P-Value } \\
\text { [Pos vs } \\
\text { Neg }^{\mathrm{a}}, 1- \\
49 \% \text { vs } \\
\geq 50 \%{ }^{\mathrm{b}} \text { ] }\end{array}$ \\
\hline $\begin{array}{l}\text { Total number of } \\
\text { cases, N (\%) }\end{array}$ & 80 & $51(63.7)$ & 29 (36.3) & 17 (21.3) & $12(15.0)$ & \\
\hline $\begin{array}{l}\text { Age in years, } \\
\text { median (range) }\end{array}$ & $\begin{array}{c}61.3 \\
(19.1- \\
87.3)\end{array}$ & $\begin{array}{c}63.9(28.1- \\
83.9)\end{array}$ & $56.3(19.1-87.3)$ & $61.6(29.7-87.3)$ & $49.4(19.1-65.6)$ & $0.09,0.023$ \\
\hline Thymoma & $40(50.0)$ & $34(85)$ & $6(15.0)(1.5 ; 1-5)$ & $6(15.0)(1.5 ; 1-5)$ & 0 & $<0.001$ \\
\hline Type A & 24 & $21(87.5)$ & $3(12.5)(1 ; 1-5)$ & 3 (12.5) (1;1-5) & 0 & 0.07 \\
\hline Type B3 & 9 & 8 (88.9) & $1(11.1)(1)$ & $1(11.1)(1)$ & 0 & \\
\hline $\begin{array}{l}\text { Micronodular } \\
\text { thymoma with } \\
\text { lymphoid stroma }\end{array}$ & 7 & $5(71.4)$ & $2(28.6)(3.5,2-5)$ & $2(28.6)(3.5,2-5)$ & 0 & \\
\hline Thymic carcinoma & $33(41.3)$ & $14(42.4)$ & $\begin{array}{c}19(57.6) \\
(50 ; 1-100)\end{array}$ & $\begin{array}{c}9(27.3) \\
(10 ; 1-30)\end{array}$ & $\begin{array}{c}10(30.3) \\
(85 ; 50-100)\end{array}$ & \\
\hline $\begin{array}{l}\text { Squamous cell } \\
\text { carcinoma }\end{array}$ & 23 & $7(30.4)$ & 16 (69.6) (40;1-100) & 8 (34.8) (10;1-30) & 8 (34.8) (90;50-100) & \\
\hline Adenocarcinoma & 4 & $4(100.0)$ & 0 & 0 & 0 & \\
\hline $\begin{array}{l}\text { Mucoepidermoid } \\
\text { carcinoma }\end{array}$ & 2 & $2(100.0)$ & 0 & 0 & 0 & \\
\hline $\begin{array}{l}\text { Lymphoepithelial } \\
\text { carcinoma }\end{array}$ & 2 & $0(0.0)$ & $\begin{array}{c}2 \text { (100.0) } \\
\text { (70; } 70 \text { each) }\end{array}$ & 0 & $\begin{array}{c}2 \text { (100.0) } \\
\text { (70; } 70 \text { each) }\end{array}$ & \\
\hline $\begin{array}{l}\text { Adenosquamous } \\
\text { carcinoma }\end{array}$ & 1 & $0(0.0)$ & $1(100.0)(5)$ & $1(100.0)(5)$ & 0 & \\
\hline $\begin{array}{l}\text { Undifferentiated } \\
\text { carcinoma }\end{array}$ & 1 & $1(100.0)$ & 0 & 0 & 0 & \\
\hline $\begin{array}{l}\text { Thymic } \\
\text { neuroendocrine } \\
\text { tumor }\end{array}$ & $7(8.8)$ & $3(42.9)$ & $\begin{array}{c}4(57.1) \\
(52.5 ; 2-100)\end{array}$ & $\begin{array}{c}2(28.6) \\
(6.0 ; 2-10)\end{array}$ & $\begin{array}{c}2(28.6) \\
(97.5 ; 95-100)\end{array}$ & \\
\hline $\begin{array}{l}\text { Atypical carcinoid } \\
\text { tumor }\end{array}$ & 5 & $3(60.0)$ & 2 (40.0) (52.5;10-95) & $1(20.0)(10)$ & 1 (20.0) (95) & \\
\hline $\begin{array}{l}\text { Small cell } \\
\text { carcinoma }\end{array}$ & 2 & $0(0.0)$ & $2(100.0)(51 ; 2-100)$ & $1(50.0)(2)$ & $1(50.0)(100)$ & \\
\hline TNM Stage & & & & & & $0.10,0.22$ \\
\hline 1 & $28(52.8)$ & $20(71.4)$ & 8 (28.6) (3.5; 1-70) & 7 (25.0) (2; 1-10) & $1(3.6)(70)$ & \\
\hline$\|$ & $1(1.9)$ & $1(100.0)$ & 0 & 0 & 0 & \\
\hline$\| \mathrm{A}$ & $4(7.5)$ & $1(25.0)$ & 3 (75.0) (90; 10-95) & $1(25.0)(10)$ & 2 (50.0) (92.5; 90-95) & \\
\hline IVA & 15 (28.3) & 8 (53.3) & $\begin{array}{c}7(46.7) \\
(90.0 ; 1-100)\end{array}$ & $\begin{array}{c}3(20.0) \\
(10.0 ; 1-30)\end{array}$ & $\begin{array}{c}4(26.7) \\
(95.0 ; 90-100)\end{array}$ & \\
\hline IVB & $5(9.4)$ & $2(40.0)$ & $3(60.0)(5.0 ; 5-70)$ & 2 (40.0) (5 each) & 1 (20.0) (70) & \\
\hline N/A & 27 & $19(70.4)$ & $\begin{array}{c}8(29.6) \\
(37.5 ; 1-100)\end{array}$ & $\begin{array}{c}4(14.8) \\
(7.5 ; 1-25)\end{array}$ & $\begin{array}{c}4(14.8) \\
(75.0 ; 50-100)\end{array}$ & \\
\hline
\end{tabular}

${ }^{a} P$-value for comparison of positive vs negative SSTR2 expression (1-100\% vs <1\%) between thymoma, thymic carcinoma, and thymic neuroendocrine tumor.

${ }^{b}$ P-value for comparison of SSTR2 expression (1-49\% vs $\geq 50 \%$ ) between thymoma, thymic carcinoma and thymic neuroendocrine tumor (excluding those with $<1 \%$ expression). N/A, not available.

As compared to those with lower SSTR2 expression (1-49\% of tumor cells), those with $\geq 50 \%$ tumor cells expression were younger in age $(\mathrm{p}=0.023)$. Also, SSTR2 expression in $\geq 50 \%$ of tumor cells trended to be more common in thymic carcinomas when compared to TNET and thymoma $(\mathrm{p}=0.056)$. SSTR2 expression (1-100\%) was more commonly seen in TET of patients with high stage (stages IIIA-IVB; 13 of $24,54.2 \%$ ) compared to patients with low stage (stage I; 8 of $28,28.6 \%$ ) tumors although that was not statistically significant $(\mathrm{p}=0.10)$. The distribution of tumor stage in relationship to the subtype of TET is summarized in Table 3 .

SSTR2 expression in $\geq 50 \%$ of tumor cells was associated with worse RFS with an estimated 5-year RFS of $11.4 \%$ (95\% CI: 0\%$32.5 \%$ ) vs $72.7 \%$ (95\% CI: $46.4 \%-99.0 \%)$ in patients with $1-49 \%$ of tumor cells expressing SSTR2 ( $\mathrm{p}=0.007)$. The estimated 5-year RFS among patients with $<1 \%$ SSTR2 expression was $67.8 \%(95 \%$ CI: $51.3 \%-84.3 \%$; $\mathrm{p}=0.10$ for $<1 \%$ vs $1-100 \%$ SSTR2 expression). SSTR2 expression was not associated with 5-year OS (estimated 66.3\% [95\% CI: 34.4\%-98.2\%], 67.9\% [95\% CI: 41.7\%-94.1\%], $69.2 \%$ [53.5\%-84.9\%] for patients with $\geq 50 \%, 1-49 \%,<1 \%$ tumor cells expressing SSTR2, respectively; $\mathrm{p}=0.71$ for $<1 \%$ vs $1-100 \%$ SSTR2 expression; $\mathrm{p}=0.96$ for $\geq 50 \%$ vs $1-49 \%$ SSTR2 expression).

\section{Results of 68Ga-DOTATATE Scans and Correlation With Clinicopathologic Features and SSTR2 Expression}

68Ga-DOTATATE PET scans were available in 9 patients. The results of the scans are presented in Table 4 . Scans were available 
TABLE 3 | Stage distribution of thymic epithelial tumors of the study population $(\mathrm{N}=53)^{\mathrm{a}}$.

\begin{tabular}{|c|c|c|c|}
\hline Stage & Thymoma Type (N) & Thymic Carcinoma & Thymic Neuroendocrine Tumor \\
\hline \multirow[t]{3}{*}{ I } & $A(16)$ & Squamous cell carcinoma (2) & Small cell carcinoma (1) \\
\hline & $\mathrm{B} 3(5)$ & Adenocarcinoma (1) & \\
\hline & Micronodular thymoma with lymphoid stroma (3) & & \\
\hline$\|$ & & Squamous cell carcinoma (1) & \\
\hline IIIA & Micronodular thymoma with lymphoid stroma (1) & Squamous cell carcinoma (3) & \\
\hline \multirow[t]{2}{*}{ IVA } & B3 (1) & Squamous cell carcinoma (8) & Atypical carcinoid tumor (4) \\
\hline & & Adenocarcinoma (2) & \\
\hline \multirow[t]{4}{*}{ IVB } & & Squamous cell carcinoma (1) & Atypical carcinoid tumor (1) \\
\hline & & Adenosquamous carcinoma (1) & \\
\hline & & Lymphoepithelial carcinoma (1) & \\
\hline & & Undifferentiated carcinoma (1) & \\
\hline
\end{tabular}

${ }^{a}$ Only includes patients with primary tumors and available staging.

from 6 patients with TNET including 5 patients with atypical carcinoid tumor and 1 patient with small cell carcinoma. In addition, scans were available from 2 patients with squamous cell carcinoma and one patient with type B3 thymoma. In 3 patients the scan was performed at some time after resection of the primary tumor. Krenning score 3 was identified in cases of atypical carcinoid tumor, small cell carcinoma, and squamous cell carcinoma $(\mathrm{N}=1$, each). The small cell carcinoma also showed strong expression of SSTR2 in $100 \%$ of the tumor cells (Figure 1), the atypical carcinoid tumor showed moderate SSTR2 expression in 95\% of tumor cells and the squamous cell carcinoma exhibited strong SSTR2 expression in $5 \%$ of tumor cells. "Increased uptake" was reported in an additional squamous cell carcinoma which had $0 \%$ of tumor cell staining with SSTR2. However, that scan was not available for re-review. Krenning score 2 was identified in 2 atypical carcinoid tumors, score 1 in an atypical carcinoid tumor (Figure 2), and no uptake was seen in an atypical carcinoid tumor and the type B3 thymoma. Interestingly, while all tumors with scans showing Krenning scores 1 or 2 or no uptake had no expression of SSTR2, the atypical carcinoid tumor with no uptake on $68 \mathrm{Ga}-\mathrm{DOTATATE}$ PET scan did show strong SSTR2 expression in $10 \%$ of the tumor cells. However, that scan was also not available for review.

All 3 patients with Krenning score 3 were treated with octreotide; none of the other patients received a somatostatin analogue treatment. One of these 3 patients who were treated with octreotide and had an atypical carcinoid tumor was metastasis and recurrence-free for 3.3 years after neoadjuvant chemotherapy, complete resection, adjuvant radiation, and adjuvant octreotide. Another patient was treated with octreotide when the thymic squamous cell carcinoma recurred. However, the patient was only treated for 3 months at which time a breast carcinoma was diagnosed and the treatment regimen was altered accordingly. Whether her disease progressed or regressed during those 3 months is unknown. The patient with small cell carcinoma was treated with octreotide for 3 months after bone metastases had developed; however, her disease progressed and therefore she underwent chemoradiation therapy 3 months later. All 3 patients were alive with disease at last follow up. None of the patients who did not undergo a $68 \mathrm{Ga}$ DOTATATE PET scan were treated with octreotide.
Both lymphoepithelial carcinomas which were EBVassociated showed strong and diffuse expression of SSTR2. A poorly differentiated squamous cell carcinoma with marked tumor infiltrating lymphocytes, morphologically reminiscent of a lymphoepithelial carcinoma but without EBV association also showed expression of SSTR2 in 90\% of tumor cells. These cases are detailed in Table 4 . Results of DOTATATE PET scans are also detailed in Table 4.

\section{DISCUSSION}

Our study of 80 retrospectively collected TET including 33 thymic carcinomas and 7 TNETs revealed expression of SSTR2 in all thymic small cell carcinomas, lymphoepithelial carcinomas, and the single adenosquamous carcinoma, three-fourths of thymic squamous cell carcinomas, and $40 \%$ of atypical carcinoid tumors. Indeed, significantly more thymic carcinomas and TNETs expressed SSTR2 than thymomas. In slightly more than half of thymic carcinomas and TNETs SSTR2 was expressed in $50 \%$ or more tumor cells. In contrast, SSTR2 was only expressed in 15\% of type A and B3 thymomas and micronodular thymomas with lymphoid stroma with expression in $5 \%$ or less of tumor cells. We also found that in all patients in whom a 68Ga-DOTATATE PET scan was available and the Krenning score was 3, the TET also expressed SSTR2 while in almost all cases of $68 \mathrm{Ga}$-DOTATATE PET scan Krenning score 1 or 2 the tumor was negative for SSTR2 expression. Our results indicate that 68Ga-DOTATATE PET scan may serve as a screening tool for SSTR2 expression in TET although confirmation of SSTR2 expression in a resection specimen may reveal an occasional TET that is negative on 68Ga-DOTATATE PET scan. Our results suggest that at least a subset of thymic carcinomas and TNETs may be responsive to somatostatin analogue treatment or SSTR2 antibody-drug conjugates while type A and B3 thymomas and micronodular thymomas with lymphoid stroma are less likely to express SSTR2 and may not respond to such treatments.

Despite our findings of low SSTR2 expression in thymomas, literature has suggested that thymomas may show response to treatment with octreotide. For instance, in a study of 15 patients with unresectable or locally recurrent thymoma and 2 patients 
TABLE 4 | Summary of patients with available DOTATATE scan.

\begin{tabular}{|c|c|c|c|c|c|c|}
\hline Case & WHO Type & pTNM & $\begin{array}{l}\% \text { (Intensity) } \\
\text { SSTR2-positive } \\
\text { Tumor Cells }\end{array}$ & $\begin{array}{l}\text { Krenning Score/ } \\
\text { Description of } \\
\text { Scan }\end{array}$ & $\begin{array}{l}\text { Treatment with } \\
\text { Octreotide/ } \\
\text { somatostatin } \\
\text { analogue }\end{array}$ & Treatment \& Outcome \\
\hline 1 & $\begin{array}{l}\text { Squamous } \\
\text { cell } \\
\text { carcinoma }\end{array}$ & T3N1M0 & 0 & Increased uptake & No & $\begin{array}{l}\text { Incomplete resection, adjuvant radiation } \\
\text { No recurrent disease } \\
\text { Died } 4 \text { yrs after resection of unknown cause }\end{array}$ \\
\hline 2 & $\begin{array}{l}\text { Atypical } \\
\text { carcinoid } \\
\text { tumor }\end{array}$ & T3N1M0 & 10 (moderate) & No uptake & No & $\begin{array}{l}\text { Complete resection of } 3.2 \mathrm{~cm} \text { tumor; adjuvant radiation } \\
\text { First metastasis at } 15 \text { months after resection } \\
\text { Metastases/recurrence to lymph nodes, bone, pleura, mediastinum, lung, } \\
\text { brain } \\
\text { DOD } 3.5 \text { years after resection }\end{array}$ \\
\hline 3 & $\begin{array}{l}\text { Atypical } \\
\text { carcinoid } \\
\text { tumor }\end{array}$ & T3N1M0 & 95 (moderate) & 3 & Yes & $\begin{array}{l}\text { MEN1 syndrome } \\
\text { Neoadjuvant chemotherapy } \\
\text { Complete resection of } 12.5 \mathrm{~cm} \text { tumor, adjuvant radiation, octreotide } \\
\text { acetate (Sandostatin) } \\
\text { First metastasis } 3.3 \text { years after resection } \\
\text { Metastasis to pleura } \\
\text { AWD } 11.2 \text { years after resection }\end{array}$ \\
\hline 4 & $\begin{array}{l}\text { Atypical } \\
\text { carcinoid } \\
\text { tumor } \\
\text { (Figure 2) }\end{array}$ & T3N1M0 & 0 & 1 & No & $\begin{array}{l}\text { Complete resection of } 4.4 \mathrm{~cm} \text { tumor; adjuvant radiation } \\
\text { First metastases/recurrence } 3.2 \text { years after resection } \\
\text { Metastases to hilar lymph nodes, lung, mediastinum } \\
\text { AWD } 5.2 \text { years after resection }\end{array}$ \\
\hline 5 & $\begin{array}{l}\text { Atypical } \\
\text { carcinoid } \\
\text { tumor }\end{array}$ & T1N1M0 & 0 & 2 & No & $\begin{array}{l}\text { Complete resection of } 3.7 \mathrm{~cm} \text { tumor; adjuvant chemotherapy and } \\
\text { steroids } \\
\text { First metastasis } 0.3 \text { years after resection } \\
\text { Metastasis to breast } \\
\text { AWD } 2.8 \text { years after resection }\end{array}$ \\
\hline 6 & $\begin{array}{l}\text { WHO type } \\
\text { B3 } \\
\text { thymoma, } \\
\text { recurrent }\end{array}$ & $\mathrm{N} / \mathrm{A}$ & 0 & $\begin{array}{l}\text { Performed } 4 \\
\text { months after } \\
\text { resection } \\
\text { Negative }\end{array}$ & No & $\begin{array}{l}\text { Resection of recurrence } 6 \text { years after initial incomplete resection, adjuvant } \\
\text { chemoradiation } \\
\text { Alive without disease } 11.7 \text { years after resection of primary tumor. }\end{array}$ \\
\hline 7 & $\begin{array}{l}\text { Squamous } \\
\text { cell } \\
\text { carcinoma }\end{array}$ & T3NXM1b & 5 (strong) & $\begin{array}{l}\text { Performed at } \\
\text { time of } \\
\text { recurrence/ } \\
\text { metastasis } \\
3\end{array}$ & Yes & $\begin{array}{l}\text { Neoadjuvant chemotherapy } \\
\text { Complete resection of } 5 \mathrm{~cm} \text { tumor; metastases to lung and liver at time } \\
\text { of initial diagnosis } \\
\text { First metastasis at } 1.4 \text { years after resection } \\
\text { Metastasis to lung } \\
4.5 \text { years after resection metastases to lymph nodes, pleura, pericardium, } \\
\text { lung - at that time Ga68-DOTATATE scan; treatment with Octreotide for } \\
3 \text { months until diagnosed with breast carcinoma } \\
\text { AWD } 7.9 \text { years after resection of primary tumor }\end{array}$ \\
\hline 8 & $\begin{array}{l}\text { Small cell } \\
\text { carcinoma } \\
\text { (Figure 1) }\end{array}$ & T1NXMO & 100 (strong) & $\begin{array}{l}3 \\
\text { Multiple } \\
\text { postoperative } \\
\text { scans with } \\
\text { scores } 3 \text { or } 4\end{array}$ & Yes & $\begin{array}{l}\text { Complete resection of } 2.7 \mathrm{~cm} \text { tumor; adjuvant chemoradiation, } \\
\text { First metastasis } 1 \text { year after resection } \\
\text { Metastases to bone; treatment with octreotide (Sandostatin) for } 3 \\
\text { months; follow up Ga68-DOTATATE showed progressive disease; } \\
\text { chemoradiation } \\
\text { AWD } 1.6 \text { years after resection of primary tumor }\end{array}$ \\
\hline 9 & $\begin{array}{l}\text { Atypical } \\
\text { carcinoid } \\
\text { tumor }\end{array}$ & T3N2M0 & 0 & $\begin{array}{l}\text { Multiple } \\
\text { postoperative } \\
\text { scans with score } \\
2\end{array}$ & No & $\begin{array}{l}\text { Complete resection of } 18.3 \mathrm{~cm} \text { tumor; neoadjuvant \& adjuvant } \\
\text { chemotherapy \& adjuvant radiation } \\
\text { First metastasis/recurrence } 0.8 \text { years after resection } \\
\text { Metastases to lung, pleura, mediastinal and abdominal lymph nodes } \\
\text { AWD } 0.9 \text { years after resection of primary tumor }\end{array}$ \\
\hline
\end{tabular}

$D O D$, died of disease; AWD, alive with disease; N/A, not applicable.

with thymic carcinoma at Masaoka stage III who had a positive octreotide scan and who were treated with octreotide and prednisone, a treatment response was found in $15(88 \%)$ patients with a median reduction of tumor volume of $51 \%$ after 12 weeks of treatment; subsequent complete surgical resection was achieved in $9(52 \%)$ patients (30). No response was observed in one of the carcinomas and a single $\mathrm{AB}$ thymoma. However, it is not clear whether the observed response in that study was indeed due to octreotide, a combined effect of prednisone and octreotide or a prednisone-only effect as studies have shown that prednisone by itself may lead to reduction in tumor volume of thymomas (36). In a similar study of 16 patients with advanced thymoma $(\mathrm{N}=10)$, thymic carcinoma $(\mathrm{N}=3)$, and thymic small cell carcinoma $(\mathrm{N}=3)$ unresponsive to conventional chemotherapy and positive octreotide scan, treatment with octreotide and prednisone resulted in a response rate of $37 \%$ with 1 complete response, 5 partial responses and 6 stable diseases (31). In a third clinical trial 


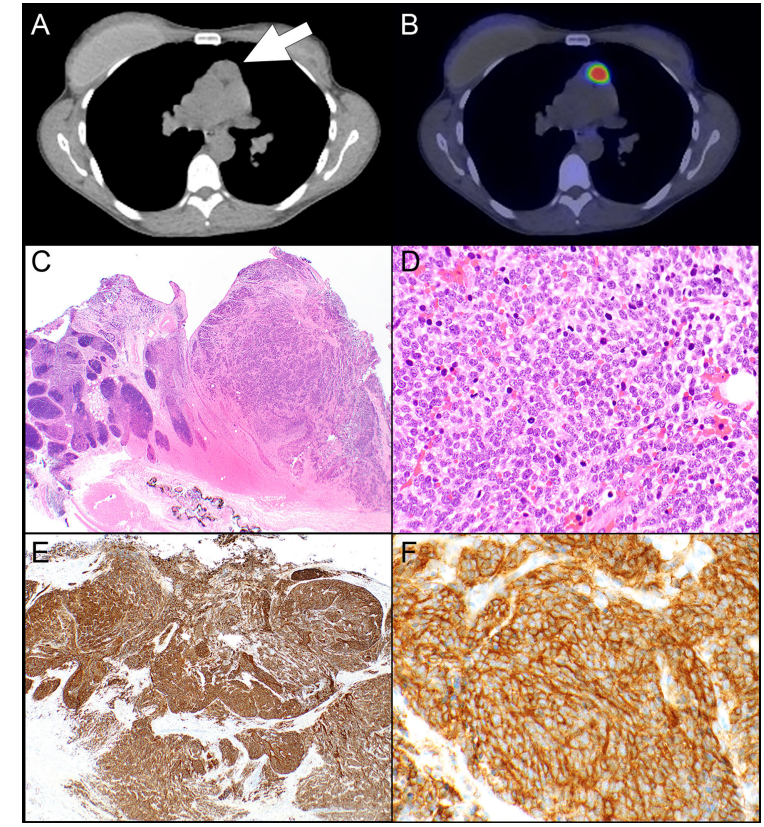

FIGURE 1 | Patient \#8. (A) A computed tomography scan shows a prevascular mediastinal lesion (arrow) that takes up 68Ga on a DOTATATE PET scan which was interpreted as Krenning score 3 (B). (C) The resection specimen shows sheets and nests of neoplastic cells (right side) in a background of thymic gland (left side). (D) The neoplastic cells are round with high nuclear-to-cytoplasmic ratio and high mitotic activity. The neoplastic cells are positive for keratin CAM5.2 (focal), synaptophysin, chromogranin (focal), and TTF-1 and negative for p63; Ki-67 shows a high proliferative index (stains not shown). (E) SSTR2 expression is diffuse and strong in virtually all tumor cells in a membranous and cytoplasmic expression pattern (F). Magnification, H\&E $\times 20$ (C), $\times 400$ (D), SSTR2 $\times 40$ (E), $\times 400$ (F).

including patients with invasive, recurrent, or metastatic thymoma $(\mathrm{N}=32)$, thymic carcinoma $(\mathrm{N}=5)$, and thymic carcinoid tumor $(\mathrm{N}=1)$ not amenable to curative therapy and positive octreotide scan, all patients were treated with octreotide for 2 cycles (32). Patients with complete or partial response would continue to be treated with octreotide, patients with stable disease received prednisone and octreotide and patients with progressive disease were removed from the study. Two (5.3\%) patients had complete response and $10(25 \%)$ had partial response with an overall response rate of $30.3 \%$. Fourteen (36.8\%) patients had stable disease. Of 38 patients treated with octreotide alone, only $4(10.5 \%)$ had a partial response. In 21 patients in whom prednisone was added there were 2 complete and 6 partial responses. All responses occurred in patients with thymoma. While these studies did not investigate the expression of SSTR2 in the tumor tissue, conceivably thymomas did express SSTR2 given the positive octreotide scans and the response to octreotide treatment in a small subset of patients. However, since tissue was not examined for SSTR2 expression in these thymomas it remains unclear whether SSTR2 was expressed in thymocytes, tumor cells or both. That may be one of the reasons for the discrepancy with our findings as we only included

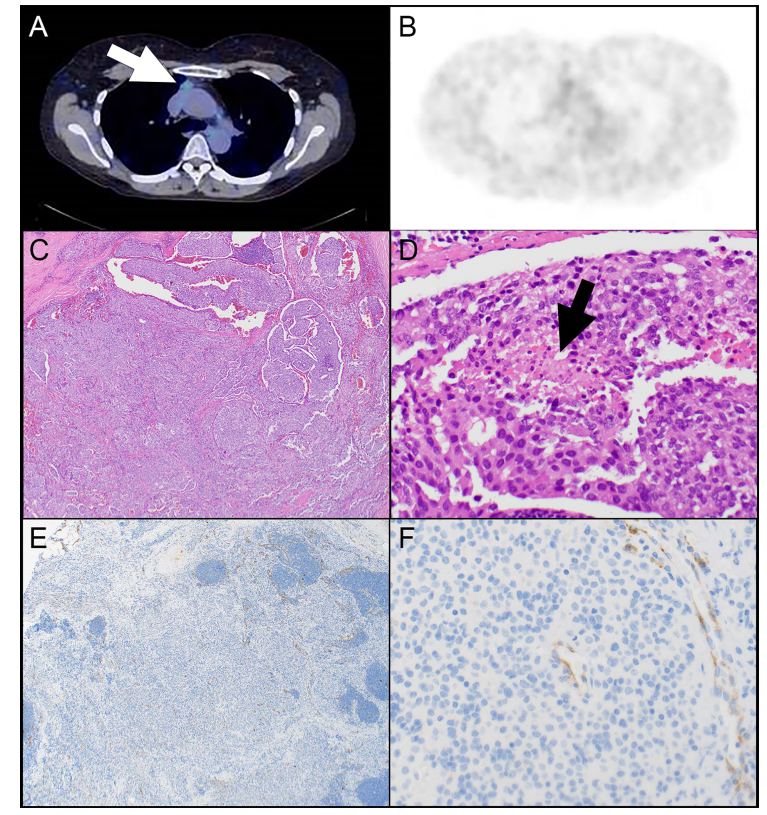

FIGURE 2 | Patient \#4. (A) A computed tomography scan shows a prevascular mediastinal lesion (arrow) that shows 68Ga take up on a DOTATATE PET scan that is much lower than liver (interpreted as Krenning score 1) (B). (C) A nested neoplasm is comprised of round to oval cells with a small amount of cytoplasm and associated with focal necrosis (D, arrow). (E) There is no expression of SSTR2 in tumor cells. (F) Note SSTR2 expression in endothelial cells serving as internal control. Magnification, H\&E x 40 (C), $x$ 400 (D), SSTR2 x 40 (E), $\times 400$ (F).

thymomas that were rich in neoplastic cells and either lacked or contained very few thymocytes. Furthermore, because none of the studies disclosed how many patients had undergone octreotide scan before patients were selected for these trials the incidence of SSTR2 expression in thymomas could not be estimated.

Both of our lymphoepithelial carcinomas, which were associated with EBV, showed strong and diffuse expression of SSTR2. This finding is consistent with a recent study by Lechner et al. that showed that in EBV-driven nasopharyngeal carcinomas the expression of SSTR2 is induced by EBV latent membrane protein 1 via the NF- $\kappa B$ pathway (23). Indeed in that study 252 of 311 (81\%) nasopharyngeal carcinomas expressed SSTR2 and SSTR2 expression was enriched in EBV-positive and in non-keratinizing nasopharyngeal carcinomas. Similarly, Viswanathan et al. in a study of primary, recurrent, and/or undifferentiated nasopharyngeal carcinomas, showed multifocal to diffuse strong SSTR2 expression in 90\% of tumors including 8 of $9 \mathrm{EBV}$-associated and one EBV-negative nasopharyngeal carcinoma (37). While one HPV-positive sinonasal carcinoma also showed patchy SSTR2 staining, the remaining HPV-positive sinonasal carcinomas, HPV-positive oropharyngeal squamous cell carcinomas, or oral cavity head and neck squamous cell carcinomas did not reveal any significant SSTR2 staining. Similarly, SSTR2 expression and 68Ga-DOTATATE uptake 
were observed in pulmonary lymphoepithelial carcinomas which also were associated with $\operatorname{EBV}(23,38)$. However, not all carcinomas and TNETs that expressed SSTR2 in our and other studies were EBV-related and therefore other pathways for expression of SSTR2 must exist in these tumors. Interestingly, one of our study cases, a poorly differentiated thymic squamous cell carcinoma with marked lymphocytic tumor infiltrate at least suggestive of lymphoepithelial carcinoma but without EBV expression also showed strong and diffuse expression of SSTR2.

SSTR2 has been shown to be expressed in a subset of neuroendocrine tumors. A study by Popa et al. suggested that SSTR2 expression may be more common in low grade than in high grade neuroendocrine tumors (39). That study showed that $96 \%$ of G1, $71 \%$ of G2 and only $23 \%$ of G3 tumors expressed SSTR2. In addition, only $33 \%$ of neuroendocrine carcinomas were SSTR2 positive which was significantly lower than in well differentiated neuroendocrine tumors. We could not confirm that finding in TNETs as we found that only $40 \%$ of atypical carcinoid tumors expressed SSTR2 while 100\% of small cell carcinomas expressed that marker. However, our overall number of TNETs was low which could have at least contributed to that discrepancy.

Evidence also suggests that SSTR2 expression may be more common in early than in late tumor stages in neuroendocrine tumors. In the study by Popa et al. of gastrointestinal neuroendocrine tumors, SSTR2 expression was 100\% in tumors of early stage while only $56 \%$ of advanced stage tumors expressed SSTR2 (39). Interestingly, in our study SSTR2 expression was overall more commonly seen in advanced stage tumors (stages IIIA, IVA, IVB) than in stage I tumors although there was no statistically significant difference. However, that finding may have been biased by the case distribution as carcinomas and TNET were more commonly of high stage while thymomas were of low stage in our study. In addition, most of our cases were not neuroendocrine tumors in contrast to the study by Popa et al. Unfortunately, we were not able to compare the expression of SSTR2 between low and high stage for thymic carcinomas and TNETs separately due to the relative low number of cases.

In 9 of our cases 68Ga-DOTATATE PET scans were available. The results of the $68 \mathrm{Ga}$-DOTATATE PET scans appeared to correlate with the expression of the SSTR2 protein by immunohistochemistry. Indeed in 2 patients with Krenning score of 3 tumors showed strong and diffuse SSTR2 expression. A third patient with a scan of Krenning score 3 had strong SSTR2 expression in $10 \%$ of tumor cells. In contrast, all cases with Krenning score 2 and lower had no SSTR2 expression in tumor cells except one atypical carcinoid tumor in which the scan reportedly did not show any uptake but the tissue showed moderate expression of SSTR2 in 10\% of tumor cells. A potential reason for that apparent discrepancy may be that standard uptake value (SUV) per voxel is used to create a PET scan in $3 \mathrm{D}$. SUV is a mathematical best estimate of how much radiotracer is in each voxel at a given point in time. In the case of a $68 \mathrm{Ga}$-DOTATATE PET scan the point in time is 60 minutes after injection. SUV is not a direct measure of how many tumor cells express SSTR2. Nor is SUV a measure of how many copies of SSTR2 are expressed on a given cell. SUV is a measure of both and other factors as well. SUV is a measure of radiotracer per voxel, which is likely correlated to the amount of SSTR2 expressed on cells in a voxel. Therefore, if the tumor cells expressing SSTR2 are spread out in 3D space, perhaps due to dead cells, extracellular fibrosis or other structures in the voxel, the SUV will go down, and as such the Krenning score will go down. Our findings of the correlation between $68 \mathrm{Ga}$ DOTATATE PET scan and SSTR2 expression in tissue are supported by the study by Lechner et al (23) of nasopharyngeal carcinomas. In that study the authors found a significant correlation between SSTR2 expression levels and uptake of $68 \mathrm{Ga}$ DOTATATE suggesting that this imaging modality may have potential as a noninvasive marker to monitor SSTR2 expression and as a target for SSTR2 receptor-targeted radionuclide therapy. This was also shown in an earlier study by Miederer et al. that evaluated a variety of neuroendocrine tumors of the gastrointestinal and pancreatobiliary tract, lung, thyroid, and thymoma and confirmed that the SUV of the 68Ga-DOTATATE scan correlated with the score of SSTR2 expression in the respective tissue (40). In a study of lung neuroendocrine tumors, SSTR2 expression in tissue correlated with octreotide scintigraphy in $71 \%$ of cases $(41)$.

In our study, age was associated with SSTR2 expression in that patients with TET that expressed SSTR2 in at least $50 \%$ of the tumor cells were significantly younger than patients with TET that expressed SSTR2 in 1-49\% of tumor cells. While this appears to be a new finding it may, at least in part, be because patients with thymic carcinomas and TNETs were younger than patients with thymoma and SSTR2 was more commonly expressed in thymic carcinomas and TNETs than in thymomas. A multivariate analysis could not be performed given the relative low number of patients.

Our study has several limitations. Although this is one of the largest case series of TET, the overall number of patients who had a 68Ga-DOTATATE PET scan available was relatively small. Furthermore, a comparison group of patients with TET treated with octreotide despite a negative 68Ga-DOTATATE PET scan was not available. Given the low number of cases survival analysis was limited. Also, because of the paucity of TET, patients included in this study were recruited between 1969 and 2021, a relatively long time span during which treatment regimens may have changed. Furthermore, while antigen expression is in general relatively stable in formalin-fixed paraffin-embedded tissue, various fixatives used over time and some degradation are possibilities and could potentially account for lower or lack of expression of SSTR2 in some tumors.

\section{CONCLUSIONS}

SSTR2 expression in TET, specifically lymphoepithelial carcinomas, squamous cell carcinomas, atypical carcinoid tumors, and small cell carcinomas may be a biomarker to 
identify patients who may respond to octreotide therapy. G68DOTATATE PET scan may be useful to predict expression of SSTR2 in tissue; however, it cannot predict whether SSTR2 is expressed in tumor cells or other cells such as inflammatory cells. Larger, ideally multi-institutional studies are necessary to independently and prospectively validate our results and to correlate SSTR2 expression in TETs and/or 68Ga-DOTATATE PET scans with response to octreotide therapy.

\section{DATA AVAILABILITY STATEMENT}

The original contributions presented in the study are included in the article. Further inquiries can be directed to the corresponding author.

\section{ETHICS STATEMENT}

The studies involving human participants were reviewed and approved by Mayo Clinic Rochester Institutional Review Board.

\section{REFERENCES}

1. Roden AC, Fang W, Shen Y, Carter BW, White DB, Jenkins SM, et al. Distribution of Mediastinal Lesions Across Multi-Institutional, International, Radiology Databases. J Thorac Oncol (2020) 15:568-79. doi: 10.1016/ j.jtho.2019.12.108

2. Roden AC, Yi ES, Cassivi SD, Jenkins SM, Garces YI, Aubry MC. Clinicopathological Features of Thymic Carcinomas and the Impact of Histopathological Agreement on Prognostical Studies. Eur J Cardiothorac Surg (2013) 43:1131-9. doi: 10.1093/ejcts/ezs529

3. Hishida T, Nomura S, Yano M, Asamura H, Yamashita M, Ohde Y, et al. Long-Term Outcome and Prognostic Factors of Surgically Treated Thymic Carcinoma: Results of 306 Cases From a Japanese Nationwide Database Study. Eur J Cardiothorac Surg (2016) 49:835-41. doi: 10.1093/ejcts/ezv239

4. Zhao Y, Gu H, Fan L, Han K, Yang J, Zhao H. Comparison of Clinical Features and Survival Between Thymic Carcinoma and Thymic Carcinoid Patients. Eur J Cardiothorac Surg (2017) 52:33-8. doi: 10.1093/ejcts/ezx037

5. Sakane T, Murase T, Okuda K, Saida K, Masaki A, Yamada T, et al. A Mutation Analysis of the EGFR Pathway Genes, RAS, EGFR, PIK3CA, AKT1 and BRAF, and TP53 Gene in Thymic Carcinoma and Thymoma Type a/B3. Histopathology (2019) 75:755-66. doi: 10.1111/his.13936

6. Bakhos CT, Salami AC, Kaiser LR, Petrov RV, Abbas AE. Thymic Neuroendocrine Tumors and Thymic Carcinoma: Demographics, Treatment, and Survival. Innovations (Phila) (2020) 15:468-74. doi: $10.1177 / 1556984520949287$

7. Bohnenberger H, Strobel P. Recent Advances and Conceptual Changes in the Classification of Neuroendocrine Tumors of the Thymus. Virchows Arch (2021) 478:129-35. doi: 10.1007/s00428-021-03037-1

8. Radovich M, Pickering CR, Felau I, Ha G, Zhang H, Jo H, et al. The Integrated Genomic Landscape of Thymic Epithelial Tumors. Cancer Cell (2018) 33:244-58. doi: 10.1016/j.ccell.2018.01.003

9. Giaccone G, Kim C, Thompson J, McGuire C, Kallakury B, Chahine JJ, et al. Pembrolizumab in Patients With Thymic Carcinoma: A Single-Arm, SingleCentre, Phase 2 Study. Lancet Oncol (2018) 19:347-55. doi: 10.1016/S14702045(18)30062-7

10. Petrini I, Meltzer PS, Kim IK, Lucchi M, Park KS, Fontanini G, et al. A Specific Missense Mutation in GTF2I Occurs at High Frequency in Thymic Epithelial Tumors. Nat Genet (2014) 46:844-9. doi: 10.1038/ng.3016

11. Nathany S, Tripathi R, Mehta A. Gene of the Month: GTF2I. J Clin Pathol (2021) 74:1-4. doi: 10.1136/jclinpath-2020-207013
Written informed consent for participation was not required for this study in accordance with the national legislation and the institutional requirements.

\section{AUTHOR CONTRIBUTIONS}

AR, GJ, and AM contributed to the conception and design of the study. AR and SR collected patient information. AR reviewed histologic sections of all cases. GJ reviewed the DOTATATE scans. SJ performed the statistical analysis. AR wrote the first draft of the manuscript. All authors contributed to manuscript revision, read, and approved the submitted version.

\section{FUNDING}

Mayo Clinic receives funding from Novartis to support research performed by GJ. The funder was not involved in the study design, collection, analysis, interpretation of data, the writing of this article or the decision to submit it for publication.

12. Tiseo M, Damato A, Longo L, Barbieri F, Bertolini F, Stefani A, et al. Analysis of a Panel of Druggable Gene Mutations and of ALK and PD-L1 Expression in a Series of Thymic Epithelial Tumors (TETs). Lung Cancer (2017) 104:24-30. doi: 10.1016/j.lungcan.2016.12.005

13. Schirosi L, Nannini N, Nicoli D, Cavazza A, Valli R, Buti S, et al. Activating CKIT Mutations in a Subset of Thymic Carcinoma and Response to Different C-KIT Inhibitors. Ann Oncol (2012) 23:2409-14. doi: 10.1093/annonc/ mdr626

14. Simonelli M, Zucali PA, Suter MB, Lorenzi E, Rubino L, Fatuzzo G, et al. Targeted Therapy for Thymic Epithelial Tumors: A New Horizon? Review of the Literature and Two Cases Reports. Future Oncol (2015) 11:1223-32. doi: $10.2217 /$ fon. 14.318

15. Aesif SW, Aubry MC, Yi ES, Kloft-Nelson SM, Jenkins SM, Spears GM, et al. Loss of P16ink4a Expression and Homozygous CDKN2A Deletion Are Associated With Worse Outcome and Younger Age in Thymic Carcinomas. J Thorac Oncol (2017) 12:860-71. doi: 10.1016/j.jtho.2017.01.028

16. Enkner F, Pichlhofer B, Zaharie AT, Krunic M, Holper TM, Janik S, et al. Molecular Profiling of Thymoma and Thymic Carcinoma: Genetic Differences and Potential Novel Therapeutic Targets. Pathol Oncol Res (2017) 23:551-64. doi: 10.1007/s12253-016-0144-8

17. Katsuya Y, Fujita Y, Horinouchi H, Ohe Y, Watanabe S, Tsuta K. Immunohistochemical Status of PD-L1 in Thymoma and Thymic Carcinoma. Lung Cancer (2015) 88:154-9. doi: 10.1016/j.lungcan. 2015.03.003

18. Yokoyama S, Miyoshi H, Nishi T, Hashiguchi T, Mitsuoka M, Takamori S, et al. Clinicopathologic and Prognostic Implications of Programmed Death Ligand 1 Expression in Thymoma. Ann Thorac Surg (2016) 101:1361-9. doi: 10.1016/j.athoracsur.2015.10.044

19. Terra S, Mansfield AS, Vrana JA, Roden AC. Heterogeneity of Programmed Death-Ligand 1 Expression in Thymic Epithelial Tumours Between Initial Specimen and Synchronous or Metachronous Metastases or Recurrences. Histopathology (2019) 74:364-7. doi: 10.1111/his.13750

20. Sakane T, Murase T, Okuda K, Takino H, Masaki A, Oda R, et al. A Comparative Study of PD-L1 Immunohistochemical Assays With Four Reliable Antibodies in Thymic Carcinoma. Oncotarget (2018) 9:6993-7009. doi: 10.18632 /oncotarget. 24075

21. Lehman JM, Hoeksema MD, Staub J, Qian J, Harris B, Callison JC, et al. Somatostatin Receptor 2 Signaling Promotes Growth and Tumor Survival in Small-Cell Lung Cancer. Int J Cancer (2019) 144:1104-14. doi: 10.1002/ ijc. 31771 
22. Lehman JM. Amassion PP: Somatostatin Receptor 2 Targeting in Small Cell Lung Carcinoma: Perspectives. Oncotarget (2019) 10:4727-30. doi: 10.18632/ oncotarget. 27107

23. Lechner M, Schartinger VH, Steele CD, Nei WL, Ooft ML, Schreiber LM, et al. Somatostatin Receptor 2 Expression in Nasopharyngeal Cancer is Induced by Epstein Barr Virus Infection: Impact on Prognosis, Imaging and Therapy. Nat Commun (2021) 12:117. doi: 10.1038/s41467-020-20308-8

24. Janssen I, Chen CC, Taieb D, Patronas NJ, Millo CM, Adams KT, et al. 68gaDOTATATE PET/CT in the Localization of Head and Neck Paragangliomas Compared With Other Functional Imaging Modalities and CT/MRI. J Nucl Med (2016) 57:186-91. doi: 10.2967/jnumed.115.161018

25. Ivanidze J, Roytman M, Sasson A, Skafida M, Fahey TJ 3rd, Osborne JR, et al. Molecular Imaging and Therapy of Somatostatin Receptor Positive Tumors. Clin Imaging (2019) 56:146-54. doi: 10.1016/j.clinimag.2019.04.006

26. Boettcher AN. Somatostatin Receptor Type 2 as an Imaging and Treatment Target for Thyroid Cancer. Radiol Imaging Cancer (2021) 3:e219009. doi: 10.1148/rycan.2021219009

27. Stueven AK, Kayser A, Wetz C, Amthauer H, Wree A, Tacke F, et al. Somatostatin Analogues in the Treatment of Neuroendocrine Tumors: Past, Present and Future. Int J Mol Sci (2019) 20. doi: 10.3390/ijms20123049

28. Thakur S, Daley B, Millo C, Cochran C, Jacobson O, Lu H, et al. (177)LuDOTA-EB-TATE, a Radiolabeled Analogue of Somatostatin Receptor Type 2, for the Imaging and Treatment of Thyroid Cancer. Clin Cancer Res (2021) 27:1399-409. doi: 10.1158/1078-0432.CCR-20-3453

29. Caplin ME, Pavel M, Ruszniewski P. Lanreotide in Metastatic Enteropancreatic Neuroendocrine Tumors. N Engl J Med (2014) 371:15567. doi: 10.1056/NEJMoa1316158

30. Kirzinger L, Boy S, Marienhagen J, Schuierer G, Neu R, Ried M, et al. Octreotide LAR and Prednisone as Neoadjuvant Treatment in Patients With Primary or Locally Recurrent Unresectable Thymic Tumors: A Phase II Study. PloS One (2016) 11:e0168215. doi: 10.1371/journal.pone.0168215

31. Palmieri G, Montella L, Martignetti A, Muto P, Di Vizio D, De Chiara A, et al. Somatostatin Analogs and Prednisone in Advanced Refractory Thymic Tumors. Cancer (2002) 94:1414-20. doi: 10.1002/cncr.10374

32. Loehrer PJSr., Wang W, Johnson DH, Aisner SC, Ettinger DS. Octreotide Alone or With Prednisone in Patients With Advanced Thymoma and Thymic Carcinoma: An Eastern Cooperative Oncology Group Phase II Trial. J Clin Oncol (2004) 22:293-9. doi: 10.1200/JCO.2004.02.047

33. Thoracic Tumours. WHO Classification of Tumours 5ed. Lyon, France: International Agency for Research on Cancer (2021).

34. Amin MBAmerican Joint Committee on Cancer and American Cancer Society. AJCC Cancer Staging Manual. BA Mahul, SB Edge, DM Gress, LR Meyer, editors. Chicago IL: American Joint Committee on Cancer, Springer (2017).

35. Volante M, Brizzi MP, Faggiano A, La Rosa S, Rapa I, Ferrero A, et al. Somatostatin Receptor Type 2a Immunohistochemistry in Neuroendocrine Tumors: A Proposal of Scoring System Correlated With Somatostatin Receptor Scintigraphy. Mod Pathol (2007) 20:1172-82. doi: 10.1038/ modpathol.3800954
36. Hu E, Levine J. Chemotherapy of Malignant Thymoma. Case Report and Review of the Literature. Cancer (1986) 57:1101-4. doi: 10.1002/1097-0142 (19860315)57:6<1101::AID-CNCR2820570606>3.0.CO;2-A

37. Viswanathan K, Sadow PM. Somatostatin Receptor 2 is Highly Sensitive and Specific for Epstein-Barr Virus-Associated Nasopharyngeal Carcinoma. Hum Pathol (2021) 117:88-100. doi: 10.1016/j.humpath.2021.08.004

38. Shang Q, Pang Y, Meng T, Hao B, Chen H. 68ga-DOTATATE PET/CT in Primary Pulmonary Lymphoepithelioma-Like Carcinoma. Clin Nucl Med (2021). doi: 10.1097/RLU.0000000000003857

39. Popa O, Taban SM, Pantea S, Plopeanu AD, Barna RA, Cornianu M, et al. The New WHO Classification of Gastrointestinal Neuroendocrine Tumors and Immunohistochemical Expression of Somatostatin Receptor 2 and 5. Exp Ther Med (2021) 22:1179. doi: 10.3892/etm.2021.10613

40. Miederer M, Seidl S, Buck A, Scheidhauer K, Wester HJ, Schwaiger M, et al. Correlation of Immunohistopathological Expression of Somatostatin Receptor 2 With Standardised Uptake Values in 68Ga-DOTATOC PET/Ct. Eur J Nucl Med Mol Imaging (2009) 36:48-52. doi: 10.1007/s00259-0080944-5

41. Righi L, Volante M, Tavaglione V, Bille A, Daniele L, Angusti T, et al. Somatostatin Receptor Tissue Distribution in Lung Neuroendocrine Tumours: A Clinicopathologic and Immunohistochemical Study of 218 'Clinically Aggressive' Cases. Ann Oncol (2010) 21:548-55. doi: 10.1093/ annonc/mdp334

Conflict of Interest: AM reports research support from the NIH, DoD, Mark Foundation, Novartis and Verily; remuneration to his institution for participation on advisory boards for AbbVie, Astra Zeneca, BeiGene, BMS, Genentech and Janssen; travel support and payment from Shanghai Roche Pharmaceuticals Ltd.; and is a nonremunerated director of the Mesothelioma Applied Research Foundation. GJ reports that Mayo Clinic receives research funding from Novartis to support his work and that he is on the Advisory Board, Novartis.

The remaining authors declare that the research was conducted in the absence of any commercial or financial relationships that could be construed as a potential conflict of interest.

Publisher's Note: All claims expressed in this article are solely those of the authors and do not necessarily represent those of their affiliated organizations, or those of the publisher, the editors and the reviewers. Any product that may be evaluated in this article, or claim that may be made by its manufacturer, is not guaranteed or endorsed by the publisher.

Copyright (c) 2022 Roden, Rakshit, Johnson, Jenkins and Mansfield. This is an openaccess article distributed under the terms of the Creative Commons Attribution License (CC BY). The use, distribution or reproduction in other forums is permitted, provided the original author(s) and the copyright owner(s) are credited and that the original publication in this journal is cited, in accordance with accepted academic practice. No use, distribution or reproduction is permitted which does not comply with these terms. 